\title{
The effect of prophylactic knee bracing on proprioception performance in first division rugby union players
}

\author{
T H Kruger (BSc Hons Biokinetics, MSc Sports Injuries) \\ M F Coetsee (BSc Hons Biokinetics, MSc, PhD) \\ $S$ Davies (BA Hons, MA Ergonomics, PhD)
}

Department of Human Movement Science, University of Zululand, Empangeni, KwaZulu-Natal

\begin{abstract}
Objective. To investigate the effects of prophylactic knee bracing on proprioceptive performance among first division rugby union players during a 2-minute Wilknox Quad Time Logger balancing task.

Design. Each subject performed a 2-minute balancing task on the Wilknox Quad Time Logger. Test order, left or right leg, and the sequence of brace or non-brace, were randomised. Subjects were placed on the balancing board and instructed to balance for 2 minutes. Subjects performed 6 trials. Two days elapsed between testing. Each testing day involved 2 trials, 1 trial with and 1 without the prophylactic knee brace.

Settings. Testing took place at the biokinetics laboratory of the University of Zululand.

Subjects. Thirty playing (not injured) male rugby players, aged 22 - 30 years, participating in the KwaZulu-Natal club championships (2000).

Outcome measure. Performance was measured in terms of time that balance was lost in a dynamic balance test. Peak proprioception was the best balancing performance recorded, and average proprioception the average balancing performance for all trials.

Results. The findings showed an improvement of $17.9 \%$ in average proprioception times and $19.1 \%$ in peak proprioception times with the application of a prophylactic knee brace $(p<0.01)$.

Conclusion. Prophylactic knee bracing improved proprioception performance of playing (uninjured) rugby players, and therefore may be responsible for the improvement in knee injury statistics reported in some studies on knee bracing.
\end{abstract}

\section{CORRESPONDENCE:}

T Kruger

P O Box 51421

Wierdapark

0149

Tel: 072-199 0388, 012-6540504

Fax: 012-654 0504

E-mail: theo@universe.co.za

\section{Introduction}

In the last 10 years sport in general and rugby in particular, has become increasingly professional, resulting in players being paid to participate in the sport. Large companies have seen the marketing potential, through worldwide media television and sponsorship, and players have used the opportunity to make rugby a career. As inter-company competition to sponsor rugby teams has increased, so has the money involved in the sport. All these factors have led to great competitiveness between players, with individuals striving to become the best player in their club, province and country. This has resulted in rugby becoming more professional especially at international level, in improved training techniques, and in greater physical demands on the players.

According to Powell ${ }^{19}$ and Pritchett ${ }^{20}$ approximately $13 \%$ of high school and college football injuries involve the knee. Well over 1000000 Americans participate in organised contact football and over 500000 South Africans in rugby union each year. Johnston and Paulos ${ }^{11}$ stated that the potential for lost playing time and the cost of providing medical care for knee injuries, not to mention the impact on a young athlete's life, make the pursuit of injury-reducing factors worthwhile.

A variety of protective and supportive knee devices have been devised because of the high incidence of injuries to this joint. Prophylactic knee braces are designed to prevent or reduce the severity of knee injuries by absorbing the valgusproducing forces. ${ }^{6,15,16,22}$ These braces have gained tremendous popularity in the last decade, and team physicians and coaches have prescribed or required brace-wearing by athletes, hoping to prevent injuries and improve performance., ${ }^{9,21}$ Branch and Hunter ${ }^{3}$ and McNaire et al. ${ }^{14}$ examined joint kinematics and muscle activity. They compared braced with nonbraced conditions and observed an increase in electromyographic activity and joint kinematics during functional tasks. However, biomechanical studies examining impacts on cadavers/surrogates have shown that braces are effective only during impacts in which the associated forces are much lower than those experienced in the sporting environment. ${ }^{14,17}$ Based on these findings, it has been suggested that proprioception may be improved with the application of a prophylactic knee brace, and this may be responsible for the decrease in knee injuries recorded with brace wearing. ${ }^{3,11,13}$ This was supported in Swash $^{22}$ and Barrett et al. ${ }^{2}$ who have shown that elastic bandaging improves proprioception in osteoarthritic and replaced knees. 
Proprioception is a very difficult parameter to define and measure. Traditionally it has been defined as an awareness of joint position in space as sensed by the central nervous system. ${ }^{23}$ It incorporates joint sensation and spatial orientation. ${ }^{13}$ The central nervous system receives information from specialised nerve endings, or mechanoreceptors, that are located in the skin, muscle, tendon, joint capsule, and ligaments. ${ }^{1}$ Proprioception is the action-reaction mechanism whereby sensory awareness of changes in the knee joint protect it against harmful forces, which is an important factor in maintaining joint stability. Therefore voluntary and spinal reflexes are important in sending messages to the muscles to react and protect the body. ${ }^{23}$ Thus if the muscles are fatigued, voluntary and spinal reflex times increase and proprioception performance decreases, resulting in decreased joint stability and an increase in the probability of injury. ${ }^{18,23}$

Review of the literature allows us to speculate as to the mechanism of improved knee proprioception seen with brace application. Certainly, afferent receptors in the skin, muscle, anterior cruciate ligament (ACL), and joint capsule exist, and these contribute to proprioceptive input. Major position sense receptors in the joint capsule and ligaments, such as free nerve endings and Golgi tendon organ stretch receptors, would likely be too deep to be affected significantly by the brace. ${ }^{4,5,8,10,18}$ The prophylactic brace certainly stimulates the skin during joint motion and also increases the pressure on the underlying musculature and joint capsule. Therefore, the most plausible receptors to be involved are the rapidly adapting superficial receptors in the skin and layers beneath muscle such as free nerve endings, hair end organs and Merkel's discs. These receptors react strongly to new stimuli, such as movement of the brace on the skin, and adapt quickly once the motion becomes monotonous. ${ }^{4,5,10,18}$

Proprioceptive ability is an important part of running, jumping and tackling and is therefore important for rugby union players throughout the game for a period of $80 \mathrm{~min}$ utes. To date, most studies have examined proprioception using static position tasks, where the subject's one limb is positioned at a certain degree angle and the subject is requested to match the position with the other limb.

The present study was designed to extend observations by providing a method of examining the ongoing effects of prophylactic knee bracing on the proprioceptive ability of playing (uninjured) rugby players, with no discernable knee pathology, during a 2-minute balancing task. This method could be a more reliable test for rugby union players than the static tests (matching the limb position) done in previous research.

\section{Methods}

Thirty male subjects playing first league rugby in the KwaZulu-Natal club championships in 2000 were randomly selected from a group of volunteers (10 forwards and 20 backline players). Prior to participation, the testing procedures and risks were fully explained, and all subjects signed an informed consent form. None of the subjects had any knee injuries at the time of the study and subjects were free to withdraw at any time. The Ethics Committee of the University of Zululand, South Africa approved the research protocol.
Proprioception testing was administered in the air-conditioned biokinetics laboratory of the University of Zululand, with at least 2 days rest between testing days. The temperature in the biokinetics laboratory was kept at $26^{\circ} \mathrm{C}$, and a relative humidity of $45 \%-55 \%$ was maintained. The test was explained and demonstrated to the subjects to ensure that they understood fully so that they could complete the test successfully. Before all tests the subjects underwent a 15-minute warm-up, including full body stretching, jogging and sprinting led by the physical trainer of the local rugby team. Prior to testing, subjects practised all procedures for 1 minute with and 1 minute without the brace. Test order, leg order, and sequence of brace or non-brace, were randomised.

Standard, off-the-shelf prophylactic knee braces (Medac (Pty) Ltd, Cape Town, South Africa) were used in the study. The basic designs of prophylactic braces are similar, consisting essentially of thigh and calf cuffs connected by hinged bars, which allow for flexion and extension of the knee (Figs 1 and 2).
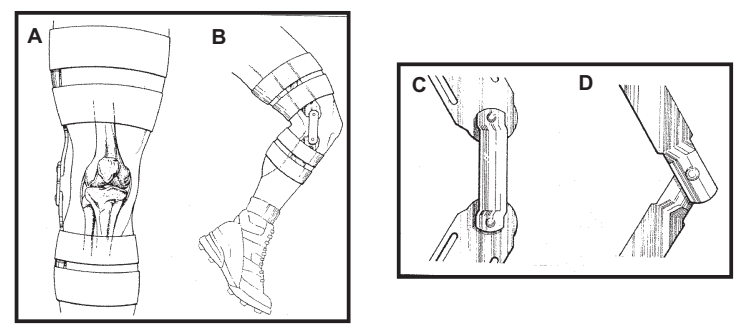

Fig. 1. The basic design of knee braces: (A) Anterior view, (B) Lateral view of thigh and calf cuffs, (C) Double hinge, and (D) single hinge.

The Wilknox Quad Time Logger is an electronic wobble board that times the loss of dynamic balance during a 2minute session. It was designed and built at the University of Zululand, South Africa. The wobble board consists of a round platform with a diameter of $350 \mathrm{~mm}$ and a thickness of $30 \mathrm{~mm}$. In the middle of the underside a half sphere with a diameter of $100 \mathrm{~mm}$ is attached. The device recorded the time that the edge of the wobble board touched the floor (Fig. 3). As the device was developed in the Department of Human Movement Science, University of Zululand, reliability was verified by means of extensive testing.

Prior to testing subjects were given a trial run of 1 minute with and without the prophylactic brace. Each subject was expected to perform 6 trials in full rugby kit and boots, 3 without the prophylactic brace and 3 with the application of the prophylactic brace. The brace was fitted randomly and the straps were tightened before each trial. Subjects were placed on the Wilknox Quad Time Logger with their feet parallel to the sides (25 cm apart), and their knees slightly bent. Subjects were prohibited from using their hands or other body parts to assist their balance by pushing against their surrounds. Subjects were instructed to balance the Time Logger for a period of 2 minutes; as soon as they were ready, timing started. The average unbalanced time (s) and the peak unbalanced times for the 3 trials in braced v. nonbraced were recorded and used to determine whether differences existed between braced and non-braced conditions. 


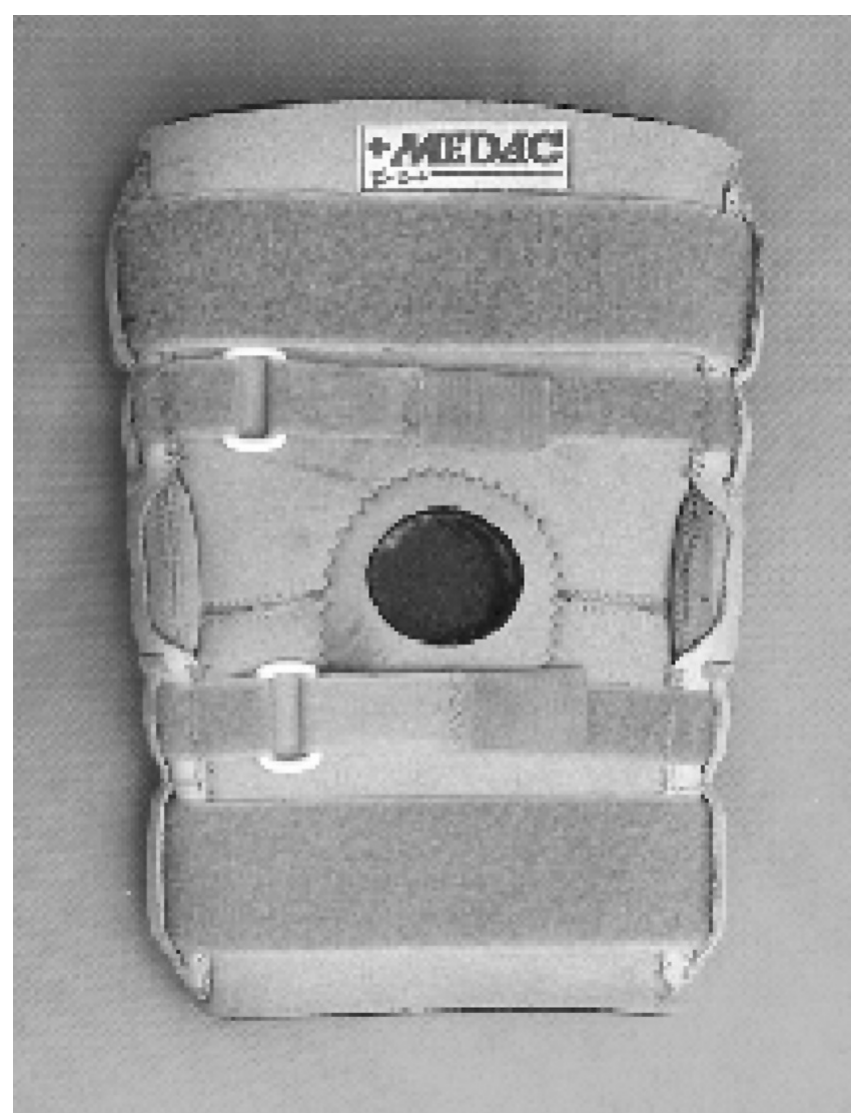

Fig. 2. Standard, off-the-shelf, Medac prophylactic knee brace.

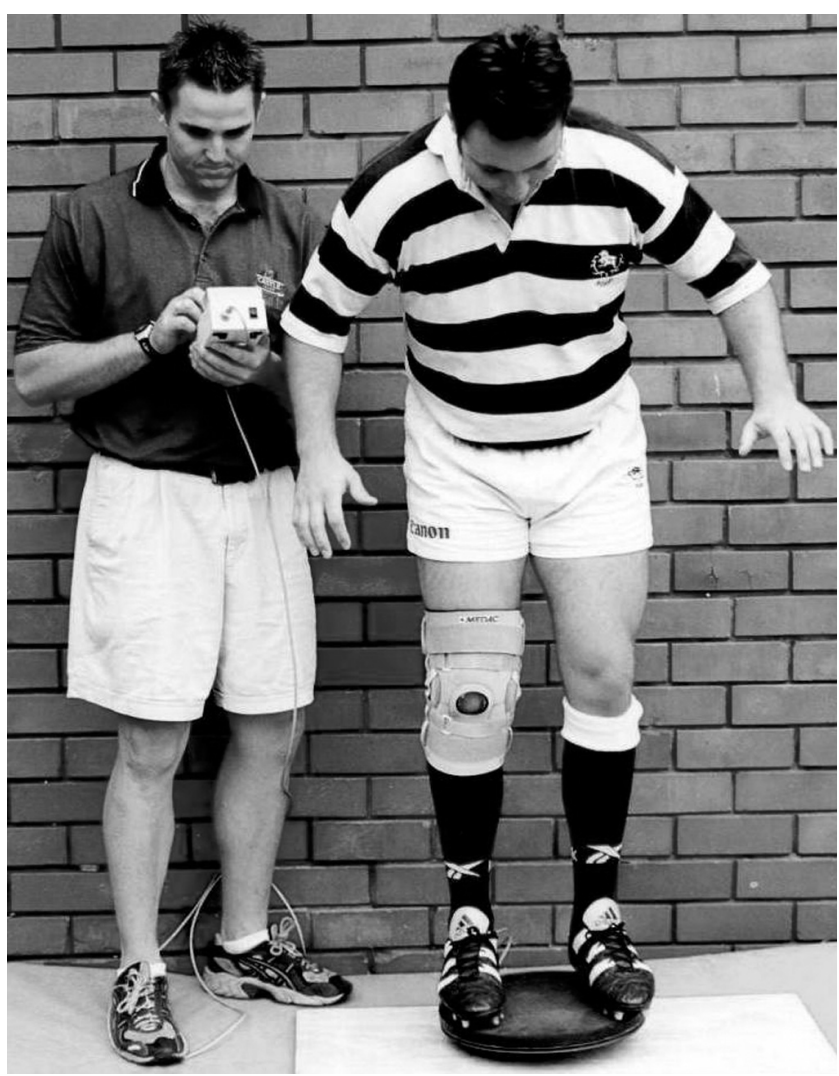

Fig. 3. Proprioception being measured on the Wilknox Quad Time Logger.
Results are expressed as means and standard deviations, along with one-way analysis of variance (ANOVA) and independent $t$-tests to determine whether significant $(p<0.01)$ differences occured between test re-test measured parameters.

Body mass was measured to the nearest $100 \mathrm{~g}$ on a Deco scale with subjects wearing only a pair of shorts. Stature was measured to the nearest millimetre using a stadiometer. Subjects stood erect and barefoot, with their weight evenly distributed on both feet and the head in the Frankfort horizontal plane. With heels together the subjects were instructed to inhale and stretch upward to the fullest extent. The vertical distance from the vertex to the floor in the mid-saggital plane was measured. Percentage body fat was calculated from skinfold measures at four sites: biceps, triceps, supra-iliac and sub-scapula.

\section{Results}

Subjects' characteristics are given in Table I. It is noticeable that the mass and height of the subjects in this study are greater than those of the general population, which is to be expected, as they are a selected group of rugby players and these attributes are essential to performance. Being club rugby players, where the selection base is relatively limited, they are smaller and lighter than players in teams competing at a higher level, where the selection base is larger.

Average and peak proprioceptive performance was recorded. Table II illustrates the average proprioceptive performances in the 3 trials for the forwards as a group, backline players as a group, and the forwards and backs combined as a group with and without the application of a prophylactic brace. The results for all 3 groups showed that the average proprioceptive ability significantly $(p<0.01)$ increases with prophylactic brace application. The average proprioceptive improvement for backline players was $17 \%$, for the forwards $20 \%$ and for the combined group $18 \%$. Table III illustrates the peak proprioceptive performances in the 3 trials for the forwards, backs and the combined group. The peak proprioceptive performance illustrated significant $(p<0.01)$ improvement for the backline players at $22 \%, 19 \%$ for the forwards and $19 \%$ for the combined group.

\section{Discussion}

This study investigated the effects of prophylactic knee bracing on the proprioceptive ability of playing (uninjured) first division rugby union players. The poor mechanical performance of braces in resisting impact forces, together with altered kinematics when wearing a brace during sports activ-

TABLE I. Characteristics of subjects $(N=30)$ in the present study compared with other studies

\begin{tabular}{lllll}
\hline Level & Age (yrs) & Stature (cm) & Mass (kg) & Fat \% \\
\hline Present study & $24.3(5.0)$ & $182.2(7.6)$ & $87.5(12.5)$ & $16.4(4.0)$ \\
SA norm & $18-34$ & 174.2 & 68.6 & \\
NSW Super 12 & 185.6 & 99.5 & 14.7 \\
Australia & 188.4 & 101.8 & 13.2 \\
Source: Kruger, Coetsee, Davies, 2003. ${ }^{12}$ & &
\end{tabular}


TABLE II. Average unbalanced times recorded in seconds on the Wilknox Quad Time Logger for playing rugby union players (braced vs non-braced)

\begin{tabular}{lllcc}
\hline Groups & Braced (SD) & $\begin{array}{l}\text { Non- } \\
\text { Braced (SD) }\end{array}$ & $\begin{array}{c}\% \\
\text { difference }\end{array}$ & $\begin{array}{l}\text { Significant } \\
\text { difference }\end{array}$ \\
\hline $\begin{array}{l}\text { Combined } \\
(N=30)\end{array}$ & $16.530(9.9)$ & $20.137(10.3)$ & 18 & $p<0.01$ \\
$\begin{array}{l}\text { Backs } \\
(N=20)\end{array}$ & $15.580(10.0)$ & $18.720(10.0)$ & 17 & $p<0.01$ \\
$\begin{array}{l}\text { Forwards } \\
(N=10)\end{array}$ & $18.430(9.4)$ & $22.970(10.2)$ & 20 & $p<0.05$
\end{tabular}

TABLE III. Peak unbalanced times recorded in seconds on the Wilknox Quad Time Logger for playing rugby union players (braced vs non-braced)

\begin{tabular}{llccc}
\hline Groups & Braced (SD) & $\begin{array}{c}\text { Non- } \\
\text { braced (SD) }\end{array}$ & $\begin{array}{c}\% \\
\text { difference }\end{array}$ & $\begin{array}{l}\text { Significant } \\
\text { difference }\end{array}$ \\
\hline $\begin{array}{l}\text { Combined } \\
(N=30)\end{array}$ & $14.449(9.2)$ & $17.850(9.5)$ & 19 & $p<0.01$ \\
$\begin{array}{l}\text { Backs } \\
(N=20)\end{array}$ & $11.700(9.2)$ & $15.070(9.5)$ & 22 & $p<0.01$ \\
$\begin{array}{l}\text { Forwards } \\
(N=10)\end{array}$ & $17.060(9.3)$ & $21.160(9.2)$ & 19 & $p<0.05$
\end{tabular}

ities, has led some researchers to suggest that proprioception may be the factor responsible for findings of decreased injury when wearing a brace. ${ }^{14}$ Proficiency in balance in this test relies more on the sensory feedback (proprioception) from the muscles and the joint structures of the lower limbs, than on the feedback from the vestibular apparatus in the inner ear. This is achieved by means of the smallness of the ball of the wobble board. Subjects need to control the wobble board (keeping the edge from touching the floor) without losing total body balance.

Overall, prophylactic brace application improved proprioceptive ability. Findings from the present study indicate that prophylactic knee bracing improved average proprioception performance significantly $(p>0.01)$ by $18 \%$ and peak proprioceptive ability significantly $(p>0.01)$ by $19 \%$. These findings are similar to those of Barrett et al..$^{2}$ and McNaire and colleagues, ${ }^{14}$ who showed that elastic bandaging which acts as a prophylactic brace, improved proprioceptive ability in subjects with both arthritic and normal knees respectively. This could improve position sense.

\section{Conclusion}

The finding of this work supports the research hypothesis that prophylactic knee bracing improves the proprioceptive ability of playing individuals, i.e. players with uninjured knees. Given the reported deficiencies of braces in protecting the knee against lateral and medial forces in sport situations, it may be that the improvement in proprioception may be responsible for the decrease in knee injury statistics reported in some epidemiological studies of bracing.

\section{REFERENCES}

1. Baker BE, Van Hanswyk E, Bogosian SP. A biomechanical study of the static stabilizing effect of the knee braces on the medial stability. Am J Sports Med 1989; 17 (2): 182-6.

2. Barrett DS, Cobb AG, Bentley G. Joint proprioception in normal osteoarthritic and replaced knees. J Bone Joint Surg Am 1991; 73b: 536.

3. Branch TP, Hunter R. Functional analysis of anterior cruciate ligament braces. Clin Sport Med 1990; 9: 771-97.

4. Clark FJ, Burgess RC, Chapin JW. Role of intramuscular receptors in the awareness of limb position. J Neurophysiol 1985; 54: 1529-49.

5. Corrigan JP, Cashman WF, Brady MP. Proprioception in the cruciate deficient knee. J Bone Joint Surg Am 1992; 74B: 247-50.

6. Deppen RJ, Landfried MJ. Efficacy of prophylactic knee bracing in high school football players. Journal of Sports Training 1994; 20: 243-6.

7. Durnin JVGA, Womersley J. Body fat assessed from total body density and its estimation from skinfold thickness: Measurement on 481 men and women aged 16 - 72 years. Br J Nutr 1972; 32: 77-97.

8. Guyton AC. Somatic sensation: The mechanoreceptive sensations. In: Textbook of Medical Physiology. 7th ed. Philadelphia: WB Saunders, 1986: 588-9.

9. Hansen BL, Ward JC, Diehl RC. The preventive use of the Anderson knee stabler in football. Physician of Sports Medicine 1985; 13: 75-81.

10. Horch KW, Clark FJ, Burgess PR. Awareness of joint angle under static conditions. J Neurophysiol 1975; 38: 1436-47.

11. Johnston JM, Paulos LE. Prophylactic lateral knee braces. Med Sci Sports Exerc 1991; 23: 783-7.

12. Kruger TH, Coetsee MF, Davies SHE. The effect of prophylactic knee bracing on selected performance parameters. African Journal of Physical Health Education and Recreational Dance 2003; 9 (1): 40-51.

13. Lephart SM, Pincivero DM, Giraldo JL. The role of proprioception in the management and rehabilitation of athletic injuries. Am J Sports Med 1997; 25: 130-7.

14. McNaire PJ, Stanley SN, Struass GR. Knee bracing: effects on proprioception. Arch Phys Med Rehabil 1996; 77: 287-9.

15. Millet C, Drez D. Knee braces. Orthopedics 1987; 10: 1777-80.

16. Millet C, Drez D. Principles of bracing for the anterior cruciate ligaments deficient knee. Clin Sports Med 1988; 7: 827-33.

17. Paulos LE, France EP, Rosenburg TD. The biomechanics of lateral knee bracing. Part I: response of the valgus restraints to loading. Am J Sports Med 1987; 15: 419-29.

18. Perlua R, Frank C, Fick $G$. The effect of elastic bandages on human knee proprioception in the uninjured population. Am J Sports Med 1995; 23: 251-5.

19. Powell J. Patterns of knee injuries associated with college football. Journal of Athletic Training Summer 1985; 9: 104-9.

20. Pritchett J. A statistical study of knee injuries due to football in high school athletes. J Joint Bone Surg Am 1982; 64A: 240-2.

21. Sforzo GA, Chen NM, Gold CA, Frye PA. The effect of prophylactic knee bracing on performance. Med Sci Sports Exerc 1989; 21: 254-7.

22. Swash M. Position sense in a damaged knee. J Neurol Neurosurg Psychiatry 1986; 49: 100-1.

23. Wojtys $E$ M, Kothari SU, Huston LJ. Anterior cruciate ligament functional brace use in sports. Am J Sports Med 1996; 24: 539-46. 